\title{
AOR
}

Selected Papers of \#AolR2021:

The 22nd Annual Conference of the

Association of Internet Researchers

Virtual Event / 13-16 Oct 2021

\section{GIRLS, GADGETS AND GATEKEEPERS: HOW GENDER AND CLASS ASPIRATIONS SHAPE ADOLESCENT ACCESS TO MOBILE PHONES IN MUMBAI, INDIA}

Isha Bhallamudi

UC Irvine

\section{Research Question, Context and Methods}

Indian society, broadly speaking, views mobile phones as simultaneously a cause of risk to girls and women, and a way to reduce the risks they face; as an artefact that poses dangers but also represents safety; that offers opportunities to empower individuals and at the same time the potential to disrupt the social order of class, caste and gender and its internal hierarchies. Consequently, Indian families struggle to navigate the myriad possibilities represented by the mobile phone in culturally appropriate ways, in accordance with classed and gendered boundaries. Their fears illuminate social norms and attitudes surrounding gender, sex, class, caste and the limits of independence and control. Indian adolescents, especially girls, who are transitioning to adulthood but are caught in the confines of the patriarchal, caste-based family and its rigid social norms, employ the mobile phone as a site to break boundaries, challenge social norms and otherwise fight to increase their independence. Yet, access to mobile phones is itself deeply gendered and classed in India.

Against this context, my study addresses the question: How do gender and class intersect within the family to shape differential access to mobile phones for adolescents in urban India? I address this question using a mixed-methods study. My fieldwork focused on 9th-grade students aged 13-15 in Mumbai, India, and I looked specifically at the experiences of adolescent girls. My field sites were 8 municipal (low-income) schools and international (high-income) schools across Mumbai. I conducted repeated, in-depth group interviews with 59 girls as well as paper surveys with 278 adolescents (both boys and girls). The survey data was analyzed using simple descriptive statistics, crosstabulations and chi-square tests, while the interview data was thematically coded and qualitatively analyzed.

Suggested Citation (APA): Bhallamudi, I. (2021, October). Girls, Gadgets and Gatekeepers: How Gender and Class Aspirations Shape Adolescent Access to Mobile Phones in Mumbai, India. Paper presented at AolR 2021: The 22nd Annual Conference of the Association of Internet Researchers. Virtual Event: AolR. Retrieved from http://spir.aoir.org. 


\section{Analytical Approach and Contributions}

I employ an intersectional analytical framework (Velaskar 2016) to help critique and unpack the assumptions underlying prior theorizations of gender, class and technology in India, while also allowing me to go beyond binary framings that read the circumstances of one set of women as 'free', therefore 'empowered', and the other as 'constrained', therefore 'bad', and understand that all women operate under specific types of gendered constraints shaped by intersectional effects of gender and caste. As Velaskar points out, it is important to go beyond using intersectionality to highlight differential experiences and oppressions, and towards critically analyzing the social and material relations around technology that create structural differences and commonalities (Velaskar 2016). This is the approach adopted in this paper.

Another intervention made by this paper, is to contribute to literature that shows that technology use in the Global South tends to be marked by innovation, creativity and a sense of collective use (Wesolowski 2012; Steenson and Donner 2008). Unfortunately, literature on global technology use largely considers mobile phones as personal and private devices operated by single users and often conflates ownership, access and use of mobile phones (Steenson and Donner 2008; Taylor 2019; Poushter 2016), despite the fact that the majority of the world's population relies on mobile phone sharing, which is egregiously understudied, to access mobile phones (Donner 2008). In light of this, I start by untangling questions around modes of access before going on to comment about the dynamics of use.

\section{Findings}

First, at a simple descriptive level, I found that adolescents in Mumbai accessed mobile phones in 3 ways: owning, borrowing from family members, and sharing or co-owning a phone with family members; and these modes of access were not mutually exclusive. Lower-class adolescents accessed mobile phones mainly by borrowing them from family members, but lower-class boys were more likely to own mobile phones than girls. Higher-class adolescents tended to own mobile phones, but still showed high rates of borrowing, and here boys and girls showed equal rates of ownership. This analysis already starts to show how gender and class combine to create constraining effects on access to mobile phones.

At an analytical level, I found that lower-class girls' upbringing is marked by a focus on adhering to values of class- and caste-based morality, which fashion the ideals of respectable femininity. These ideals include good academic performance, home training toward future marriage (cooking and other chores as well as care work towards male members of the family) and limiting time outside the home. The mobile phone is seen as an artefact that can threaten these practices of class aspiration and emulation, and parents consequently actively limit girls' access to them.

In contrast, higher-class girls' upbringing included a cosmopolitan and merit-based rhetoric which encouraged and taught them to cultivate independence and capability, to live up to the cosmopolitan idea of a young woman who lives life on her own terms 
without any gendered constraints weighing her down. The mobile phone plays a crucial role in mediating these aspirations and forms an important part of upward mobility, in helping girls learn and enact the practices of a global, cosmopolitan way of line and gain 'exposure'.

Rather than interpret these differences via binaries (tradition/modernity, restrictive/empowering, lower-class/upper-class), I instead consider how classed ideals of respectable femininity create different aspirational conditions for girls belonging to each class group, and form the cultural frames of everyday life. What implications might this have for adolescent girls' understandings and enactments of independence? Looking at class-gender relations around mobile phones in the context of the family helps uncover the lines of agency, domination and power emerging out of these structures and how they shape girls' and women's lives. Girls learn to operate within, subvert or resist these boundaries, which variously enable and circumscribe their full participation in public life. In these years leading up to adulthood, they face the task of mediating their own, independent aspirations and desires to fit within the framework of class stability, respectability and morality, taught to them by their families. Mobile phones play an important role in adolescent girls' negotiation of this precarious femininity, and mediate their first steps of navigating online and offline public spaces and attendant ideas of risk and safety, threaded within and against boundaries of the private and public, tradition and modernity.

\section{References}

Donner, J. (2008). Research approaches to mobile use in the developing world: A review of the literature. The information society, 24(3), 140-159.

Poushter, J. (2016). Smartphone ownership and internet usage continues to climb in emerging economies. Pew Research Center, 22, 1-44.

Steenson, M., \& Donner, J. (2009). Beyond the personal and private: Modes of mobile phone sharing in urban India. The reconstruction of space and time: Mobile communication practices, 1, 231-250.

Taylor, K., \& Silver, L. (2019). Smartphone ownership is growing rapidly around the world, but not always equally. Pew Research Center.

Velaskar, P. (2016). Theorising the interaction of caste, class and gender: A feminist sociological approach. Contributions to Indian Sociology, 50(3), 389-414.

Wesolowski, A., Eagle, N., Noor, A. M., Snow, R. W., \& Buckee, C. O. (2012). Heterogeneous mobile phone ownership and usage patterns in Kenya. PloS one, 7(4). 